\title{
TASK-BASED APPROACH: A TAREFA Comunicativa no Ensino do Italiano como LíngUa Estrangeira
}

\author{
ElisabetTa Santoro*
}

RESUMO: Tema de numerosos estudos e ensaios desde os anos 1980, o ensino baseado em tarefas comunicativas (task-based approach) despertou o interesse de linguistas e estudiosos que se dedicam ao ensino e à aprendizagem de línguas estrangeiras por propor uma visão que não se limita à aprendizagem das formas da língua e prevê múltiplas finalidades, tendo em seu horizonte a formação integral do aluno. De fato, além de estarem baseadas no sentido e em uma visão ampla da relação entre o sujeito e a língua que está aprendendo, as tarefas comunicativas procuram também fornecer a oportunidade de conhecer a língua em uso e, portanto, de tomar consciência de suas possibilidades e do que se pode fazer com a língua. Serão apresentadas neste artigo reflexões sobre a definição e sobre os conceitos ligados à tarefa comunicativa, e exemplos - baseados no italiano L2 - de como algumas mudanças na postura do professor podem transformar simples atividades de sala de aula em tarefas comunicativas.

PALAVRAS-CHAVE: ensino por tarefas; sentido; comunicação; italiano L2.

ABSTRACT: Tema di numerosi studi e saggi sin dagli anni '80, il taskbased approach ha suscitato l'interesse di linguisti e studiosi che si dedicano all'insegnamento e all'apprendimento delle lingue straniere perché propone una

* Docente da Área de Língua e Literatura Italiana da Universidade de São Paulo e do Programa de Pós-Graduação em Língua, Literatura e Cultura Italianas. 
visione che non si limita all'apprendimento delle forme della lingua e prevede, invece, finalità multiple, considerando come suo fine ultimo la formazione integrale dell'allievo. Di fatto, oltre a essere basate sul significato e su una visione ampia del rapporto tra il soggetto e la lingua che sta imparando, $i$ task cercano anche di fornire l'occasione di conoscere la lingua in uso e, pertanto, di rendere consapevoli delle sue possibilità e di ciò che si può fare con la lingua. Saranno presentate in quest'articolo riflessioni sulla definizione e sui concetti legati al task e esempi basati sull'italiano L2 di come alcuni cambiamenti nella prospettiva del docente possono trasformare semplici attività di classe in task.

PAROLE CHIAVE: task-based learning; significato; comunicazione; italiano L2.

ABSTRACT: Subject of numerous studies and essays since the 1980s, the task-based approach has attracted the interest of linguists and scholars who are dedicated to the teaching and learning of foreign languages because it proposes a vision that is not limited to learning the forms of language and provides, instead, multiple purposes, considering as its ultimate goal the integral formation of the student. In fact, besides being based on the meaning and on a broad vision of the relationship between the subject and the language he is learning, the task also seeks to provide an opportunity to get to know the language in use and, therefore, gain awareness about its possibilities and what we can do with the language. This article will present reflections on the definition and on concepts related to tasks, as well as examples, based on Italian as second language, of how certain changes in the perspective of the teacher can turn simple classroom activities into tasks.

KEYWORDS: task-based learning; meaning; communication; Italian L2. 


\section{Introdução}

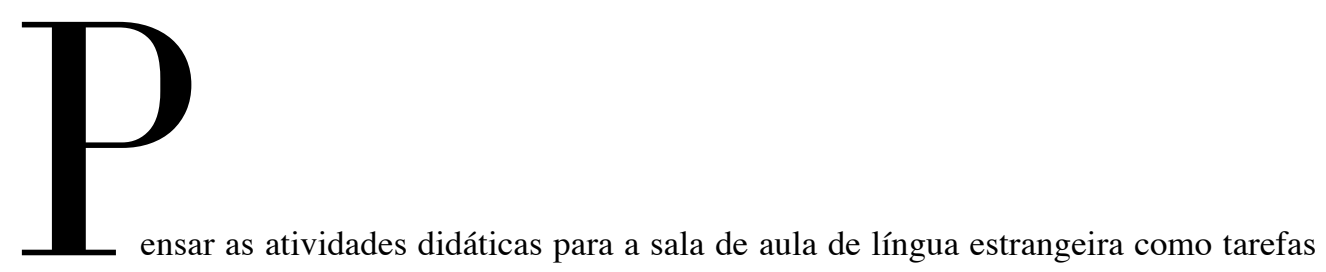

comunicativas (ou tasks) implica, primeiramente, em uma reflexão sobre a concepção de língua que subjaz à sua elaboração. Vamos começar, então, com uma afirmação: propor tarefas no ensino de línguas pressupõe considerar que uma língua, para além das normas de sua gramática e do repertório de seu léxico, possui mecanismos por meio dos quais se constroem sentidos e permite a realização da comunicação entre indivíduos - entendida não apenas como transmissão de mensagens, mas como atividade complexa.

Os objetivos das tarefas não se limitam, portanto, à aprendizagem das formas da língua, prevendo, ao contrário, múltiplas finalidades e tendo em seu horizonte a formação integral do aluno. De fato, além de estarem baseadas no sentido e em uma visão ampla da relação 
entre o sujeito e a língua que está aprendendo, as tarefas comunicativas procuram também fornecer a oportunidade de conhecer a língua em uso e, portanto, de tomar consciência de suas possibilidades e do que se pode fazer com a língua.

\section{A tarefa comunicativa: possíveis definições}

O conceito de "tarefa comunicativa" aplicado à aquisição, à aprendizagem e ao ensino de línguas estrangeiras já foi tema de inúmeros ensaios e livros ${ }^{1}$. No entanto, não há uma definição unívoca e válida para todos os contextos, pois muitas vezes os pesquisadores acabaram acrescentando ou eliminando aspectos estabelecidos em outros estudos e privilegiando as características que julgavam mais relevantes para suas reflexões.

O Quadro europeu comum de referência para as línguas: aprendizagem, ensino e avaliação (QECR) introduz o conceito de tarefa, dizendo que sua execução "envolve a activação estratégica de competências específicas, de modo a realizar um conjunto de acções significativas num determinado domínio, com uma finalidade claramente definida e um produto (output) específico" (2001, p. 217).

Os aprendizes são, portanto, envolvidos na tarefa em nível pessoal, e sua contribuição é altamente significativa para o desenvolvimento das atividades em sala de aula. Por causa disso, as atividades realizadas não serão nunca duas vezes idênticas a si mesmas, já que, a cada execução, a participação dos discentes irá produzir mudanças e reinterpretações do que foi proposto pelo professor.

Como vimos no início, uma característica essencial da tarefa é que o sentido está no centro do processo e possui uma relevância primordial (SKEHAN, 1998, p. 95). Os aprendizes devem compreender, negociar e expressar sentidos - e não reproduzir sentidos de outros de modo a apropriar-se da língua e vivenciá-la em uso. É por isso que as tarefas podem ser ditas comunicativas, pois colocam em movimento a compreensão de mensagens significativas (input), são baseadas na negociação de significado (interação) e pressupõem a produção de novas mensagens significativas (output).

1 Ver, entre outros, Nunan, 1989; Parrott, 1993; Willis, 1996; Skehan, 1998; Bygate, Skehan e Swain, 2001; Robinson, 2001. 
Reflexões dessa natureza são as que guiam os teóricos do foco na forma (focus-on-form $)^{2}$, visão que se afirma em reação, por um lado, à concepção de um ensino/aprendizagem baseado em estruturas gramaticais isoladas ("foco naS formaS" - focus-on-formS), e, por outro, a uma organização das aulas que, procurando reproduzir o ambiente de aquisição da língua materna, dirige-se apenas ao sentido, ignorando de todo a gramática, a aparência linguística e sua observação no interior do texto (foco no sentido - focus on meaning).

No entanto, embora o sentido seja essencial, chega-se a ele através da forma (veremos isso também mais à frente) e, portanto, é preciso manter "um equilíbrio instável entre a atenção prestada ao sentido e à forma" (QECR, 2001, p. 218). Em outras palavras, espera-se que os aprendizes descubram o sentido dos textos (do input) e de suas próprias produções linguísticas, levando em conta como e por quais estruturas da língua eles foram realizados e baseando-se em um equilíbrio dinâmico entre o foco na forma e o foco no sentido. Assim, os alunos percebem que, para expressar determinados sentidos, precisam de formas linguísticas que irão aprender levados por uma necessidade comunicativa e não apenas pela ideia da repetição que, segundo as crenças que por muito tempo dominaram os cursos de línguas estrangeiras, deveria conduzir à aprendizagem de estruturas, muitas vezes apresentadas de forma isolada e descontextualizada.

Na perspectiva das tarefas comunicativas, sentido e formas linguísticas, plano do conteúdo e plano da expressão, são elaborados contemporaneamente, superando e integrando abordagens que privilegiam ora um, ora outro aspecto (aspectos só lexicais, ou só morfossintáticos, ou só culturais e interculturais, ou só escritos, audiovisuais, orais etc.). A ideia-guia é que o objetivo final de todo o percurso de aquisição/aprendizagem de uma língua estrangeira é a autonomia do aprendiz, que deve desenvolver cada vez mais suas potencialidades para poder usar dentro da sala de aula e fora dela não só a língua, mas também todas as competências e os conteúdos que fazem parte do seu percurso de formação.

Há mais um aspecto que é considerado característica constitutiva de uma tarefa e que precisa ser lembrado para completar sua definição: é essencial que ela tenha relações com atividades da vida real, diferentemente do que muitas vezes acontece nas atividades linguísticas na sala de aula de língua estrangeira, que, no lugar de trazer para a escola o mundo, afastam-se dele, transformando-se em repetições ou em situações artificiais, cujo sentido não ultrapassa a prática de um aspecto limitado da língua.

2 Sobre essa questão, ver Long (1991, 1997); Long e Robinson (1998); Doughty e Williams (1998); e Ortega (2001). A maior parte desses estudos foi publicada em inglês e, portanto, a terminologia específica acabou fixando-se nessa língua. Como foi dito, para a tradução para o português nos baseamos no Glossário de Lingüística Aplicada (Almeida Filho e Schmitz, 1998), o qual, porém, não contempla todos os termos utilizados, indicando que eles ainda não possuem uma tradução consolidada. Decidimos, portanto, para maior clareza, que as traduções seriam seguidas pela designação em inglês. 
Cabe aqui uma observação sobre o que entendemos por vida real, pois, hoje, ainda na esteira do que foi propagado pelo comunicativismo, considera-se muitas vezes que aspectos da dita vida real são apenas os que dizem respeito a situações de comunicação corrente e utilitária. Entretanto, nossa vida real não é constituída apenas por situações desse tipo e não são raras as ocasiões nas quais nossas necessidades linguísticas vão muito além das fórmulas ou das estruturas por meio das quais podemos, por exemplo, pedir algo, fazer perguntas, falar do que fazemos durante o dia ou do que fizemos em um passado mais ou menos recente.

Por exemplo, textos com função estética - muitas vezes negligenciados nos cursos de línguas estrangeiras ou deixados para a parte final do percurso - fazem parte do nosso cotidiano: música, cinema e literatura estão presentes em nossa vida, estão cada vez mais acessíveis e são procurados pelos aprendizes também em língua estrangeira, portanto incluí-los na prática da sala de aula apenas espelha situações que vivemos habitualmente.

Além disso, é preciso pensar que atividades menos frequentes na vida de alguns aprendizes podem ser, para outros, absolutamente comuns. Para alunos de um curso de Letras, por exemplo, as atividades de ler e analisar textos literários são certamente parte do cotidiano, já que estão presentes nas aulas de várias disciplinas, estendem-se a outros momentos de sua formação e provavelmente de sua vida particular, e continuarão presentes em sua futura vida profissional, em que os textos e a literatura serão essenciais. Por isso, para esses alunos será importante aprender a ler textos literários desde o início do desenvolvimento de sua relação com a língua estrangeira.

\section{O ensino por tarefas e a sala de aula}

Dito isso, podemos afirmar que, por suas características, o ensino por tarefas (task-based approach) se opõe às formas tradicionais de ensino/aprendizagem de línguas estrangeiras nas quais, muitas vezes, a prática de estruturas linguísticas ou de situações artificiais (inclusive as ditas "comunicativas") acabava prevalecendo, transformando o aluno em um mero repetidor de formas gramaticais, de expressões fixas e de um léxico pré-estabelecido por meio dos quais o aprendiz deveria atingir o domínio da língua estrangeira.

Em uma direção contraposta a isso, os estudiosos que refletem sobre a tarefa no ensino de línguas enfatizam, como vimos, que toda atividade desenvolvida em sala de aula precisa privilegiar o sentido e ser executada para realizar um objetivo, um resultado concreto (outcome) e com valor comunicativo, ao qual se chega utilizando a língua estrangeira. Em outras palavras, a aquisição/aprendizagem da língua estrangeira não acontece só por meio da prática de estruturas 
e funções (como quando, por exemplo, o aluno faz um exercício para treinar uma determinada forma gramatical ou elabora um diálogo para usar uma específica função linguística), mas é inserida em um processo mais abrangente e múltiplo no qual há metas a serem alcançadas por meio da língua estrangeira.

Para completar o quadro de características que consideramos fundamentais para identificar as tarefas, podemos dizer que, ao contrário dos exercícios que dão destaque especificamente à prática de formas, estas:

- pretendem

envolver ativamente os aprendizes numa comunicação real e significativa;

- são relevantes (interessam o aqui e agora ou têm relação com ele);

- são exigentes, mas realizáveis;

- apresentam

resultados comunicativos identificáveis e imediatos, além de outros, menos evidentes na hora de sua realização, que se podem manifestar com o tempo.

Há obviamente uma gradação que vai do mais distante ao mais próximo de uma tarefa. Assim, propor um exercício no qual se repetem frases isoladas para treinar uma determinada forma gramatical como, por exemplo, as clássicas séries de perguntas e respostas para exercitar o uso de pronomes ou frases com lacunas que devem ser preenchidas utilizando a estrutura gramatical estudada, são escolhas que desconsideram qualquer participação do sentido, pois os aprendizes tenderão a não considerar o que as frases significam e, mesmo que o façam, essas frases não poderão produzir sentidos autênticos porque não correspondem a uma necessidade comunicativa. Ao contrário, a primeira consequência da utilização da tarefa em sala de aula 
é que toda a língua que os alunos produzem será autêntica ${ }^{3}$, isto é, criada para uma efetiva comunicação de conceitos e conteúdos e não apenas para reproduzir situações artificiais ou para aprender específicas estruturas da língua estrangeira. Assim, pratica-se a língua enquanto se desenvolvem competências e habilidades muito mais amplas, em atividades mais complexas, mas que os alunos têm condições de levar a termo, inclusive porque motivados por um contexto em que o óbvio é substituído pelo desafiador, o artificial pelo autêntico, o facilitado pelo complexo, estimulando-os a participar ativamente.

Muitas vezes, na prática da sala de aula, pequenas mudanças podem ser suficientes para começar a ver os aprendizes e sua aquisição/aprendizagem da língua estrangeira de uma maneira diferente e para ajudá-los a construir uma relação de maior autonomia com a língua que estão aprendendo. Nas atividades que privilegiam a produção, criadas para a sala de aula, é possível estabelecer uma ligação com a realidade dentro e fora da classe; naquelas que, ao contrário, são ao mesmo tempo de recepção e produção, podem ser propostos textos da realidade, a partir dos quais se elaboram tarefas significativas que recriam as condições de uso da língua. Um simples exemplo da minha prática de professora de italiano para estrangeiros pode ajudar a esclarecer como. Vejamos.

É muito comum que a alunos de um curso de italiano se faça uma proposta de atividade parecida com a seguinte: "Raccontate il vostro fine-settimana, alternando il passato prossimo e l'imperfetto". Embora se peça aos alunos a narração de acontecimentos pertencentes à sua vida real, e a atividade tenha, portanto, algumas características de uma tarefa, o enunciado escolhido para indicar como devem desenvolver a atividade revela qual é a principal preocupação do professor e merece algumas reflexões.

Vale observar que pedir aos aprendizes que alternem o uso de passato prossimo e imperfetto obriga-os a pôr em primeiro plano a escolha do tempo verbal, isto é, a focalizar as formas em detrimento do sentido (focus on formS vs. focus on meaning). Bastaria eliminar a menção

$3 \mathrm{O}$ conceito de autenticidade é um dos mais debatidos e polêmicos no âmbito do ensino/aprendizagem de línguas estrangeiras. Fala-se em autenticidade, em primeiro lugar, para definir um insumo (input) que não é criado para fins didáticos nem alterado para eliminar dificuldades, mas existem também outras interpretações possíveis. Aqui, por exemplo, estamos utilizando o conceito de autenticidade para definir a "língua utilizada para uma finalidade não artificial", ou seja: os aprendizes falam em sala de aula e se comunicam para obter algo real, diferente do que pode acontecer quando o aluno finge uma determinada situação para treinar uma estrutura linguística. Nesse sentido, embora concordemos com os que afirmam que língua é intrinsecamente cultura (VEDOVELLI, 2002, p. 118), acreditamos que só a língua para comunicar “de verdade” seja de fato significativa e possa criar uma real motivação. 
explícita dos tempos verbais para permitir que os aprendizes se concentrem primordialmente nos sentidos que querem transmitir, e que as formas linguísticas sirvam ao sentido, como geralmente acontece na comunicação real, quando o que importa é expressar ideias e conteúdos e precisamos selecionar estruturas linguísticas adequadas para fazê-lo. Dizendo, então, apenas: "Raccontate il vostro fine-settimana" se poderia alcançar o seguinte resultado: os alunos chegam autonomamente à escolha dos tempos verbais, decidem como contar suas experiências e acabam, desta forma, tendo um papel ativo e uma maior consciência de quais estruturas linguísticas são necessárias para expressar determinados sentidos. Será altamente provável que, para realizar a tarefa proposta, eles tenham que utilizar exatamente os tempos verbais que o docente espera. No entanto, acontece que, caso isso não seja feito, serão os próprios alunos que eventualmente irão sentir falta de formas verbais apropriadas, o que poderá levá-los a pedir a ajuda do professor e a querer indicações mais precisas. Além disso, se a atividade for realizada em grupo, pode-se prever que a interação produzirá nos aprendizes a percepção de como, por meio dos diferentes tempos do passado da língua italiana, é possível falar de ações aspectualmente distintas.

A atividade assim modificada não excluirá, portanto, a atenção às estruturas linguísticas, mas mudará o foco. No lugar do foco nas formaS (o focus on formS que mencionamos acima), será estimulado, dessa maneira, o chamado focus on form, ou seja, uma atenção geral e contextualizada às formas da língua, orientada ao seu uso e à realização dos objetivos comunicativos do falanteaprendiz.

Para os objetivos do professor preocupado em ensinar a seus alunos formas gramaticais específicas, a atividade transformada não levará a grandes diferenças, pois, como dissemos, será praticamente inevitável que os alunos utilizem determinados tempos verbais para falar de fatos passados. Do ponto de vista de sua realização e da eficácia no ensino/aprendizagem, a mudança no foco da atividade será, no entanto, importante, pois será estimulada não só a motivação dos alunos, mas também sua atenção em relação aos mecanismos linguísticos por meio dos quais expressamos sentidos.

Há mais uma alteração na atividade que poderia modificar tanto sua realização quanto seus efeitos. Após a primeira alteração proposta, a consigna era a seguinte: "Raccontate il vostro finesettimana". Enunciada desta forma, a atividade não prevê que os alunos cheguem a um resultado comum e exclui, portanto, a necessidade da interação com um objetivo claro. Diferente seria, por exemplo, dizer: "Divisi in gruppi raccontate il vostro fine-settimana e scegliete poi quello che al gruppo sembra più divertente (oppure interessante, insolito ecc.) indicando le ragioni 
della vostra decisione". Desta vez, fica claro o seguinte: 1) a atividade precisa ser desenvolvida em grupos; 2) cada grupo deve chegar a um resultado concreto e comum; 3) será necessário fornecer justificativas e explicar os resultados obtidos pelos grupos. A diferença essencial é, portanto, que, propondo aos aprendizes que tenham no final um resultado comunicativo comum, estimula-se a atenção para com o próprio relato e o dos outros, além de criar-se uma produtiva interação entre os discentes. A necessidade de chegar a um produto linguístico comum leva também a dedicar maior atenção ao modo como se diz, além de propiciar uma colaboração produtiva entre os alunos, que precisam trabalhar em conjunto, argumentar para defender suas ideias e zelar para que cada membro do grupo seja representado no final.

Refletimos até agora sobre possíveis alterações em uma atividade, limitando-nos a comentar as diferenças que estas causariam. Podemos, todavia, acrescentar ainda algumas observações sobre a possibilidade de planejar o trabalho em sala de aula, prevendo que a atividade seja precedida e seguida por outros momentos. Quando a atividade é uma tarefa (task), esses momentos são chamados pré-tarefa (pre-task) e pós-tarefa (post-task). Trata-se de outras mudanças na organização das atividades didáticas, que podem modificar o modo como os alunos se relacionam com sua aprendizagem e entre si.

No exemplo citado aqui, tratamos especificamente de uma atividade de produção. Os alunos não partem de nenhum texto de base e precisam "criar a língua" a partir de seus conhecimentos e de suas experiências. No entanto, podemos elaborar hipóteses sobre quais seriam as vantagens de incluir um momento que precede a narração dos alunos. Pensando no exemplo que estamos utilizando aqui, poderíamos supor mostrar aos aprendizes cenas de filmes que retratam ações geralmente realizadas durante o final de semana e nos momentos de lazer. Em seguida, pode-se pedir a eles que escolham duas ou três cenas, procurem na sala de aula colegas que tenham selecionado as mesmas cenas e descrevam juntos uma ou duas. Desenvolvendo essa atividade antes de iniciar a narração de seu próprio final de semana, os alunos são sensibilizados, por meio de momentos de "eliciação", para que sejam trazidos à tona conhecimentos pré-existentes relativos a aspectos ligados de algum modo à atividade, e que preparam para o desenvolvimento da tarefa.

"Eliciar" (do inglês to elicit) significa, de fato, nesse contexto, "trazer à tona", "fazer aflorar", "evocar", mas também conduzir alguém para que chegue pela lógica a alguma conclusão, faça inferências, utilize um elemento do presente para "chamar" - e poder depois utilizar conhecimentos de outra maneira não imediatamente acessíveis. 
O primeiro objetivo desse tipo de atividade é o de criar motivação no aluno para a execução da atividade prevista. Cabe aqui dizer que o termo "motivação", embora amplamente utilizado nos estudos sobre ensino/aprendizagem de línguas estrangeiras, não é de tão simples definição. No nosso entendimento e para as finalidades a que nos propomos aqui, "motivação" diz respeito à direção e à magnitude de um determinado comportamento (cf. DÖRNYEI, 2001, p. 7-17). Isso significa que dizendo "motivação" fazemos referência a situações que levam os aprendizes a querer fazer algo, a ter persistência nesse fazer e a mostrar empenho em sua realização.

A pré-tarefa serve, então, para estimular o desejo de saber e a curiosidade e, portanto, para suscitar o interesse dos alunos em relação à atividade a ser desenvolvida. Essa não é, contudo, sua única finalidade. A pré-tarefa ajuda também a preparar um campo comum a toda a classe, ou seja, a estabelecer um repertório de conhecimentos prévios compartilhados, com o qual todos possam contar na hora da narração, da leitura de um texto ou do desenvolvimento de outras atividades.

Além disso, o momento da pré-tarefa pode também eliciar (trazer para o aqui e agora) conhecimentos linguísticos específicos que podem ser utilizados durante a realização da tarefa. Pode tratar-se de estruturas linguísticas presentes em um texto escrito, oral ou sincrético que se propõe e que os aprendizes podem entender com mais competência após uma (re)utilização, ou então de elementos linguísticos que podem ser usados na exposição de conteúdos próprios ou de interpretações relativas ao texto proposto.

Há ainda uma fase que pode ser acrescentada à atividade central. Trata-se da chamada póstarefa, que proporciona aos alunos um momento para refletir sobre a atividade que acabaram de desenvolver, inclusive reanalisando o que produziram individualmente ou em conjunto com os colegas. Essa fase pode ser realizada ainda em sala de aula, mas também fora dela e, uma vez encerrado o trabalho principal, constitui a parte conclusiva. Pode-se, por exemplo, pedir aos alunos que elaborem um texto escrito com o mesmo tema tratado em sala de aula, ou então, que procurem um texto ou um vídeo que tenha o mesmo assunto ou algum tipo de ligação com o que foi feito em classe.

A ideia é que os alunos (re)utilizem nessa fase do trabalho o repertório de conhecimentos adquirido durante as aulas dedicadas a um determinado tema. A língua que foi lida, ouvida, falada e escrita na sala de aula serve nesse momento para a redação do trabalho escrito ou para saber como escolher textos que serão levados para os colegas, e isso requer uma participação ativa do aluno.

Antes de concluir, é importante aqui uma reflexão sobre a execução das tarefas comunicativas, 
pensando, em especial, nas competências que o aluno necessita - e que a tarefa estimula -, nas condições e nas limitações que podem modificar o seu alcance e nas estratégias que os aprendizes precisam ativar para a sua realização.

Considerando as competências, podemos afirmar que a execução de uma tarefa requer que o aprendiz utilize e aprenda a relacionar, além de seus conhecimentos linguísticos, sua experiência de mundo, seus conhecimentos socioculturais e suas habilidades interculturais. De fato, quando é necessário desenvolver uma atividade real, não basta conhecer a língua a ser utilizada, mas é necessário colocar em jogo e, portanto, desenvolver outras competências e habilidades que permitam a realização da tarefa, garantindo a transmissão do sentido.

É preciso levar em conta também as condições colocadas pela tarefa e as limitações previstas pelo professor, que são variáveis e podem ser modificadas, podem aumentar ou diminuir a dificuldade e precisam ser adequadamente planejadas para estimular a interação e a produção na língua estrangeira. Apenas para fornecer alguns exemplos, pode ser levado em conta se há ajuda externa (contexto ou ajuda linguística); como se predispõe a organização do tempo (preparação, execução, duração dos turnos de fala, duração da tarefa); que tipo de finalidade se prevê (convergência ou divergência da finalidade da tarefa, atitude do aprendiz e do docente); qual é o grau de previsibilidade (introdução de um elemento inesperado, dinamicidade vs. estaticidade do texto); como influem as condições materiais (interferências como barulhos, lacunas na mensagem etc.); como se estrutura a relação entre os participantes (disponibilidade para a cooperação, características do discurso dos interlocutores e sua visibilidade, competência geral e comunicativa).

Além disso, pode-se considerar que a realização da tarefa por parte dos alunos será influenciada pelos seguintes fatores:

a. ajuda externa (fase preparatória que estimule o aprendiz; indicações claras, pertinentes e suficientes que permitam conhecer os objetivos e a maneira de proceder; organização em duplas ou pequenos grupos);

b. características do texto (complexidade linguística; tipologia textual; estrutura discursiva; apresentação por canais diferentes; tamanho e densidade do texto; interesse pelo tema e motivação por parte do aprendiz); 
c. tipo esperado de resposta (a tarefa pode e deve ser adequada aos aprendizes e, mesmo com um texto de partida mais difícil, o importante é que os aprendizes tenham condições para executar as atividades previstas).

Uma vez estabelecida a atividade que o professor deverá planejar atentamente e adequar aos seus alunos e aos seus objetivos, será necessário que ele ajude os aprendizes a desenvolver estratégias que poderão ser utilizadas na realização das tarefas. Trata-se de estratégias gerais e comunicativas para selecionar, compensar, ativar e coordenar as competências necessárias para o desenvolvimento da atividade. Como já vimos, as diferentes competências não se limitam ao conhecimento linguístico e, ao contrário, pressupõem que os alunos sejam capazes de articular seus conhecimentos, de modo a melhorar o resultado final e assim estimular também a aquisição da língua estrangeira.

O planejamento da tarefa e a decisão sobre quais serão suas características têm um efeito direto e imediato no seu grau de dificuldade. Se pensarmos nas competências e nas características do aprendiz, precisamos considerar, além das já citadas condições e limitações das tarefas, também os fatores cognitivos, afetivos e, obviamente, linguísticos. Quanto aos fatores cognitivos, é preciso, em primeiro lugar, analisar a familiaridade do aluno com a tarefa. Para fazer isso, será importante escolher com cuidado o tipo de tarefa, o tema geral e eventuais subtemas mais específicos, o gênero textual, as informações sobre o contexto e sobre as normas socioculturais, a consciência intercultural etc. São também necessárias habilidades de vários tipos, como as organizacionais, as relacionais, as estratégicas, as interculturais etc. Por outro lado, será essencial possuir a capacidade para lidar com as exigências de processamento. $\mathrm{O}$ aluno deverá, portanto, gerenciar as operações cognitivas, elaborar o que a tarefa requer, ligar as diferentes etapas etc. Influenciam o desenvolvimento das tarefas outros fatores, entre os quais há os afetivos, como a autoestima, o envolvimento e a motivação, as condições gerais e a atitude do aprendiz e, obviamente, os linguísticos, dos quais depende muito a realização da tarefa e como o aprendiz a perceberá. O estágio de desenvolvimento linguístico do aprendiz, sua fluência, seu nível de precisão, a complexidade linguística de que é capaz etc. terão, portanto, um papel de extrema importância e deverão ser levadas em conta na hora de escolher as atividades que serão propostas. 


\section{Conclusões}

Chegamos ao final deste texto. Refletimos sobre as tarefas comunicativas no ensino de línguas estrangeiras, pensamos em algumas de suas características e nos efeitos que podem produzir na realidade da sala de aula de língua estrangeira, na qual o aluno não é apenas um receptor e repetidor de estruturas, mas um sujeito com um papel ativo em um processo de aprendizagem que privilegia o sentido, considerando, ao mesmo tempo, a importância da forma. De fato, como procuramos mostrar, a tarefa comunicativa em sala de aula permite que o aprendiz construa uma relação com a língua estrangeira caracterizada por uma autonomia cada vez maior e pela capacidade de reconhecer que, na língua, os fatos gramaticais e as escolhas lexicais não têm relevância apenas em si, mas pelos efeitos de sentido que produzem e pelo modo como influenciam a comunicação.

\section{Referências}

ALMEIDA FILHO, J. C. P. de; SCHMITZ, J. R. Glossário de Lingüística Aplicada. Português-Inglês / Inglês-Português. Campinas: Pontes, 1998.

BYGATE, M. Effects of Task Repetition on the Structure and Control of Oral Language. In: BYGATE, M.; SKEHAN, P.; SWAIN, M. (orgs.). Researching Pedagogic Tasks. Second Language Learning, Teaching and Testing. Harlow: Pearson Education Limited, 2001, p. 23-48.

CONSELHO DA EUROPA. Quadro europeu comum de referência para as línguas. Aprendizagem, ensino, avaliação. Trad. M. J. P. do Rosário e N. V. Soares. Porto/Lisboa: Asa, 2001.

DÖRNYEI, Z. Motivation. Teaching and Researching. Edinburgh: Pearson Education Limited, 2001.

DOUGHTY, C.; LONG, M. H. (orgs.). The Handbook of Second Language Acquisition. Oxford: Blackwell, 2003.

DOUGHTY, C.; WILLIAMS, J. (orgs.). Focus on Form in Classroom Second Language Acquisition. New York: Cambridge University Press, 1998.

LONG, M. H. Focus on Form: A Design Feature in Language Teaching Methodology. In: BOT, K. de; GINSBERG, R. B.; KRAMSCH, C. (orgs.). Foreign Language Research in Cross-cultural Perspective. Amsterdã: John Benjamins, 1991, p. 39-52.

Focus on Form on Task-based Language Teaching. Annual McGraw-Hill Teleconference in Second Language Teaching. 1997. Disponível em: <http://www.mhhe.com/socscience/foreignlang/top. 
$h t m \geq$. Acesso em: 20 março 2014.

LONG, M. H.; ROBINSON, P. Focus on Form: Theory, Research, and Practice. In: DOUGHTY, C.; WILLIAMS, J. (orgs.). Focus on Form in Classroom Second Language Acquisition. Nova York: Cambridge University Press, 1998, p. 15-41.

NUNAN, D. Designing Tasks for the Communicative Classroom. Cambridge: Cambridge University Press, 1989.

ORTEGA, L. Atención implícita hacia la forma: teoría e investigación. In Estudios de lingüística. Alicante: Universidad de Alicante, 2001, p. 179-211.

PARROTT, M. Task for Language Teachers. A Resource Book for Training and Development. Cambridge: Cambridge University Press, 1993.

ROBINSON, P. (org.). Cognition and Second Language Acquisition. Cambridge: Cambridge University Press, 2001a.

. Task Complexity, Cognitive Resources, and Syllabus Design: A Triadic Framework for Examining Task Influences on SLA. In: (org.). Cognition and Second Language Acquisition. Cambridge: Cambridge University Press, 2001b, p. 287-318.

SKEHAN, P. A Cognitive Approach to Language Learning. Oxford: Oxford University Press, 1998.

VEDOVELLI, M. Guida all'italiano per stranieri. La prospettiva del Quadro comune europeo per le lingue. Roma: Carocci, 2002.

WILLIS, J. A Framework for Task-based Learning. Londres: Longman, 1996. 